\title{
Miguel Córdoba SALMerón, La teología cristiana a través del arte barroco (Colección Arte y Arqueología; sección Arte. Colección Biblioteca Teológica Granadina 44), Granada, Universidad de Granada - Facultad de Teología de Granada, 2019, 254 pp., 20,90 €. ISBN 978-84-85653-86-7.
}

https://doi.org/10.46543/ISID.2130.1014

Acorde con el interés que sigue despertando la via pulchritudinis, la Universidad de Granada y la Facultad de Teología de la misma ciudad editan un estudio titulado La teología cristiana a través del arte barroco, escrito por Miguel Córdoba Salmerón, colaborador y docente de estas instituciones respectivamente.

La publicación es todo un ejemplo de aproximación entre arte y teología, tan necesaria en nuestros días, habida cuenta de la acuciante secularización que ya no hace tan obvio el presupuesto de la fe. De ahí uno de sus méritos: ofrecer un material sistemático de doctrina católica para la interpretación del arte, centrándose en una de sus expresiones más convincentes, el Barroco, que encajó a la perfección con los intereses propagandísticos de la Contrarreforma.

La obra refleja la trayectoria académica del autor que, especializado en ambas ciencias, retomó el objeto de su tesis doctoral sobre el patrimonio del antiguo colegio jesuita de Granada con ocasión del examen de grado en Teología. Por ende, la mayoría de las obras que comenta pertenecen al citado colegio, hoy Parroquia de los santos Justo y Pastor, además de otras de Granada, su tierra natal. Asimismo, es de suponer que las abundantes referencias a las piezas del Museo de la Casa Profesa de Ciudad de México responden, aparte de a su vocación jesuítica, a su estancia en esta ciudad para un máster.

Todo esto la hace recomendable para alumnos e investigadores en historia del arte, como también para los que se disponen al examen de grado en Teología, prueba que demanda la máxima compilación de conocimientos para una síntesis teológica completa. En efecto, quien opte por su modalidad escrita verá en este trabajo un logrado ejemplo de síntesis mediante un eje vertebrador concreto, en este caso el arte. De ahí que sus ocho capítulos correspondan a los principales tratados de teología: revelación, cristología, antropología, moral, eclesiología, sacramentología, escatología y Trinidad. Compaginándolos con ejemplos tomados del arte, parte del axioma del Damasceno sobre el servicio que esta actividad presta a la evangelización:"si alguien que no 
conoce a Dios pregunta por él, acompáñale dentro de una iglesia y, a través de la decoración, explícaselo"; de modo que, por la encrucijada de la verdad y la belleza, el autor nos hace de guía para adentrarnos en las profundidades de la fe.

En el primer capítulo aborda el objeto de la teología fundamental: revelación y fe, motivo por el que se sirve de la cita con la que suele introducirse esta disciplina (1 Pe 3) y que inspira el título del epígrafe,"a través del arte podemos dar razón de nuestra fe". A este respecto, propone que el arte facilita la búsqueda de Dios, especialmente el templo, verdadero recinto teofánico, metáfora plástica de la revelación: "lo invisible que se hace visible en la experiencia estética". Muestra de ello es la iglesia del Gesù de Roma, desde la que explica las fuentes de la revelación: Sagrada Escritura y Tradición, que tienen como epicentro a Jesucristo, Palabra definitiva de Dios, a cuyo nombre todo se somete (Flp 2,9). Así lo expresa la bóveda de Giovanni Bautista Gaulli con el Triunfo del nombre de Jesús, alegoría relacionada con la eucaristía, tal y como también interpreta Juan Valdés Leal al pintar al divino Infante sobre las letras IHS, con la cruz y la sagrada forma, adorado por la Inmaculada, san Ignacio y san Francisco de Borja.

El carácter concluyente de la Palabra encarnada para la revelación conduce al segundo capítulo de índole cristológica: "lo invisible se hace visible. Quien me ve a mí ve al Padre" (Jn 14, 9)". Las representaciones de Jesús en el Barroco captan su doble naturaleza, especialmente en la Pasión: la humanidad en su cuerpo llagado y la divinidad en su expresión serena, "reflejo de lo discutido en los concilios cristológicos", además de su conciencia filial y soteriológica, traducida en títulos como el de "Cordero de Dios" (Jn 1,29), figurado por Francisco Zurbarán y Josefa de Óbidos en ese animal atado preparado para el sacrificio, símil de su cometido redentor. La preferencia por la Pasión propició otros trasuntos acerca de la identidad y misión de Jesús, como el Varón de Dolores o el que pintó Pieter Fransz de Grebber: el Resucitado, que, con las marcas de su padecimiento, es invitado por el Padre a ocupar el trono de su derecha como Kýrios, en razón del salmo 110, clave para la cristología primitiva. Incluso el doble motivo de su condena — religioso y político- puede descubrirse, según el autor, en estas obras. Todavía le da lugar de tratar la mariología, marcada por el código barroco de la amplificatio, cuya iconografía por antonomasia es la Inmaculada. A este respecto, una observación, en cuanto que no comenta algunas de las ilustraciones 
del libro, por ejemplo, la del Padre eterno pintando a la Inmaculada. Los límites inherentes a una memoria de grado lo justifican, si bien podría corregirse en una posible reedición.

La humanidad de Cristo lleva en el tercer capítulo a la antropología teológica, teniendo al hombre como"culmen de la creación". La escultura de san Francisco de Borja que talló José de Mora, absorto y con la calavera coronada de la emperatriz, le sirve de pretexto para trazar los temas existenciales que se plantea el ser humano: su origen y destino, el mal y el pecado, etc. Curiosamente reflexiona sobre la creación de Dios cual deus pictor, como artista, metáfora que apunta a que todas las cosas son"seres-pensado" por su conciencia creadora, tema que - sugiero- podría enlazarse con la iconografía inmaculista anteriormente citada. El mal y el pecado fueron objeto de representación en el Barroco, así como la gracia de Dios en los hombres, significada en los éxtasis esculpidos por Bernini de santa Teresa y la beata Ludovica, así como en los abrazos místicos de san Francisco y san Bernardo que pintaron respectivamente Murillo y Ribalta, o la Magdalena a los pies de Jesús «en donde se expresa la sobreabundancia de la gracia».

Las virtudes teologales ocupan el cuarto capítulo:"sal de tu tierra (Gn 12,1)", llamada de Dios a Abrahán que refleja el dinamismo de las virtudes en llevar al hombre a salir de sí para encontrar al Otro, sobresaliendo en ello la caridad. Frente a la sola fide, los católicos potenciaron las acciones caritativas, interpretadas en uno de los programas barrocos mejor conseguidos, el que Murillo realizara para la iglesia del Hospital de la Caridad de Sevilla, seis pinturas que junto al Entierro de Cristo de Pedro Roldán completan las siete obras de misericordia. Según el autor, los lienzos también hablan de las virtudes teologales, representadas, de hecho, en el ático del retablo mayor y en la fachada. Puesto que estas persiguen la configuración con Cristo, los lienzos de Murillo y el grupo escultórico de Roldán tienen como sujeto u objeto de la acción a Jesús mismo.Y para que no se tuviera como algo inalcanzable, Miguel Mañara, mentor del programa, encargó otras dos obras a Murillo que demostraran, a la luz de la vida de los santos - Juan de Dios e Isabel de Hungría-, que podía conseguirse. Todavía, en la tesitura de que las virtudes son don y tarea, trae La vocación de san Mateo de Caravaggio. Pasando a la moral cristiana, trata aspectos como el probabilismo, la conciencia, la libertad y el pecado como mysterium iniquitatis. A colación de esto comenta dos 
obras en las que un hombre discierne qué camino escoger, asesorado en sus flancos por dos espíritus, el bueno y el malo, si bien el último responsable de la decisión es él.

El capítulo quinto versa sobre eclesiología: "llamados a ser un único cuerpo", tratado que, frente a los protestantes, pone de relieve la fundación de la Iglesia por Cristo y su triunfo sobre estos, como representan varias pinturas de inspiración rubeniana. Igualmente, enlaza la iconografía de Cristo en hábito religioso con la idea paulina del cuerpo eclesial y su cabeza (1 Cor 10,16-17; Ef 2,11-22). Retomando la imagen del templo, sostiene que en él pueden verse las cuatro propiedades esenciales de la Iglesia: koinonía, martyría, diakonía y leitourgía. Su universalidad se plasma en la escena de los discípulos en la pesca milagrosa, la comunión del colegio apostólico en la serie del apostolado y su misión evangelizadora en retablos como el de san Francisco Javier con los tres mártires del Japón. Y así como la constitución dogmática sobre la Iglesia Lumen gentium tiene como colofón a María, acaba con la iconografía de la Virgen de la Misericordia, metáfora de su maternidad eclesial.

Uno de los tratados en los que la Contrarreforma hizo más hincapié fue el de los sacramentos, objeto del sexto capítulo: "haciendo continua memoria". Los programas iconográficos que los representan insinúan su institución por Cristo y la necesidad del ministro, destacando la Eucaristía y la Penitencia. Los retablos barrocos, espectaculares por la aparatosidad del tabernáculo, traducen la fe en la presencia real de Cristo, mientras que San Pedro en lágrimas, portada del libro, la necesaria contrición y confesión de los pecados.

El séptimo capítulo es sobre escatología, trayendo con relación a la muerte El árbol de la vida, alegoría en la que Cristo avisa tocando la campana que pende del árbol que un esqueleto tala y en cuya copa se halla un grupo en fiesta. La meditación de la muerte le lleva de nuevo a la imagen de san Francisco de Borja con la calavera en la mano, además de la vanitas, "jeroglífico de las postrimerías", interpretada magistralmente por Valdés Leal. Otro de los temas recurrentes en el Barroco por la Contrarreforma fue el purgatorio, con las almas entre llamas, consoladas o sacadas por los santos. La parusía tiene su representación en el Juicio final, si bien hay quien prefiere el particular, como Mateo Cerezo con el Juicio del alma, distinguiéndose así dos juicios, uno universal al final de la historia y otro inmediato a la muerte. La derrota de esta tiene su iconografía predilecta en la 
resurrección de Cristo, mientras que la de la muerte eterna en la de las almas atormentadas por las penas del infierno. Insistiendo en la victoria de Cristo y su extensión a los hombres como principal mensaje escatológico, comenta el Descenso a los infiernos de Alonso Cano en el que Cristo hondea triunfante una bandera, mientras coge de la muñeca a una de las almas, al tiempo que la cruz redentora asoma por detrás y Adán y Eva lo contemplan.

En el último capítulo, sobre la Trinidad, nos invita a alzar la mirada, no solo metafóricamente, sino también físicamente para reparar en las tres Personas divinas que coronan retablos, bóvedas y cúpulas. Su intelección comporta un gran esfuerzo, dada la trascendencia del misterio, alegorizado por Giovanni Lanfranco cuando pinta a san Agustín con el niño que, en vano, intenta volcar el mar con una concha en un hoyo de la playa. La iconografía escogida para la Trinidad es la de la Compasión del Padre en la que este acoge al Hijo muerto en la cruz. Bellamente representada por José de Ribera, su composición muestra la relación profunda entre las tres Personas divinas, así como su manifestación en el misterio pascual de Cristo, máxima donación del Padre en el Espíritu por amor a los hombres. El tema obliga a retomar la doctrina de los primeros concilios que confiesan a un solo Dios en tres Personas distintas. Esto propició la iconografía de la Trinidad triándica que representa a las tres Personas divinas con rasgos humanos, prohibiéndose a mitad del siglo XVIII que así se hiciese con el Espíritu Santo.

Como advierte el autor en la introducción, a pesar de la dificultad que entraña la ilustración de ciertos términos y conceptos teológicos con relación al arte, se puede decir que, tras la lectura de esta monografía, "es posible realizar una síntesis teológica en la que se combinen ambas ciencias".

\author{
Álvaro Román Villalón \\ Facultad de Teología San Isidoro de Sevilla \\ aromanvillalon@gmail.com
}

